\title{
Reação de genótipos de pessegueiro à ferrugem-da-folha
}

\author{
André Paulo Assmann(1), Idemir Citadin(2), Idalmir dos Santos ${ }^{(2)}$ e Américo Wagner Júnior ${ }^{(2)}$
}

(1)Agropantanal, Rua Campo Grande, № 1190, CEP 79560-000 Chapadão do Sul, MS. E-mail: assmann@agronomo.eng.br (2)Universidade Tecnológica Federal do Paraná, Programa de Pós-Graduação em Agronomia, Via do Conhecimento, Km 01, Caixa Postal 571, CEP 85503-390 Pato Branco, PR. E-mail: idemir@utfpr.edu.br, idalmir@utfpr.edu.br, americowagner@utfpr.edu.br

\begin{abstract}
Resumo - O objetivo deste trabalho foi identificar fontes de resistência à ferrugem-da-folha em pessegueiro. Foram realizadas três avaliações de incidência e severidade de ferrugem-da-folha em 15/1, 14/2 e 24/3 de 2005, em 17 genótipos; em 23/2/2006, a severidade foi avaliada em 12 genótipos e nos 17 já avaliados anteriormente; em 28/1/2008, avaliaram-se a incidência, a severidade e a desfolha nos 29 genótipos avaliados anteriormente, além de 'Conserva 803'; em 3/2/2008, avaliou-se o número de lesões por folha em 12 genótipos. Os dados de incidência, severidade, desfolha e número de lesões por folha, em cada ano, foram submetidos à análise de variância, e as médias dos genótipos foram comparadas pelo teste de Scott-Knott. Foram realizadas correlações de Pearson entre incidência, severidade, desfolha e lesões por folha (2008). Os dados de incidência, severidade e desfolha de 28/1/2008 e os de severidade de 23/2/2006 foram submetidos à análise multivariada. 'Olímpia' e 'Cascata 1063' apresentaram níveis aceitáveis de resistência à ferrugem-da-folha; não foi verificada imunidade à doença, mas sim eficiência de infecção diferenciada nos genótipos estudados, o que indica que o tipo de resistência encontrada pode ser horizontal. O número de lesões por folha pode ser usado para classificar genótipos de pessegueiro quanto à reação à ferrugem-da-folha.
\end{abstract}

Termos para indexação: Prunus persica, Tranzschelia discolor, resistência a doenças.

\section{Peach genotypes reaction to leaf rust}

\begin{abstract}
The objective of this work was to identify resistance sources to leaf rust in peach tree. Three evaluations of leaf rust incidence and severity were performed in 1/15, 2/14 and 03/24 of 2005 in 17 genotypes; severity was evaluated in 2/23/2006, in 12 genotypes and in the 17 ones previously evaluated; incidence, severity and defoliation were evaluated in 1/28/2008, in the 29 evaluated genotypes and in 'Conserva 803'; in 2/3/2008, lesions per leaf were determined in 12 genotypes. Analysis of variance was performed for incidence, severity, and lesions per leaf, for each year, and means were compared by Scott-Knott test. Pearson's correlation analyses were accomplished for incidence, severity, defoliation and lesion per leaf (2008). Data for incidence, severity and defoliation (1/28/2008) and severity (2/23/2006) were submitted to multivariate analysis. 'Olímpia' and 'Cascata 1063' showed acceptable levels of resistance to leaf rust; no immunity to leaf rust was detected; however, differential efficiency of infection among genotypes was observed, which indicates that the resistance could be horizontal; the number of lesions per leaf could be used to classify peach genotypes reaction to leaf rust.
\end{abstract}

Index terms: Prunus persica, Tranzschelia discolor, disease resistance.

\section{Introdução}

O pessegueiro é considerado cultura típica de clima temperado (600 a 1.200 horas de frio abaixo de $7,2^{\circ} \mathrm{C}$ ), mas atualmente é cultivado em regiões de baixo acúmulo de frio hibernal (menos de 100 horas abaixo de $7,2^{\circ} \mathrm{C}$ ). Isso se deve ao intenso trabalho de melhoramento genético na cultura, que possibilitou a criação de cultivares melhor adaptadas às diversas condições climáticas (Raseira \& Nakasu, 2002). Porém, com a expansão da cultura para regiões de clima subtropical úmido, tornou-se maior a intensidade de algumas doenças como ferrugem, causada pelo fungo Tranzschelia discolor (Fukel) Tranzschel \& Litvinov (Citadin et al., 2005; Alves \& May-De Mio, 2008). Esse fungo possui especialização fisiológica inerente aos diversos hospedeiros do gênero Prunus (Martins \& Amorim, 2000).

Essa doença possui importância econômica no Brasil e ocorre com maior intensidade nas regiões quentes e úmidas, situadas ao norte do paralelo $25^{\circ} \mathrm{S}$, nos estados do Paraná, São Paulo e Minas Gerais (Barbosa et al., 1994; Citadin et al., 2005). 
O fungo infecta mais comumente as folhas, embora possa atacar frutos e ramos. A colonização do fungo, dentro da estrutura da folha, se dá por meio dos espaços celulares subepidérmicos. O haustório geralmente desenvolve-se dentro do mesofilo foliar ou logo abaixo da camada de células corticais, e não há colonização de tecidos cambiais e vasculares. As lesões são delimitadas pelas nervuras, com sintomas de pequenas manchas amareladas na superfície adaxial, enquanto que as pústulas ou urédias com seus uredósporos, encontramse na superfície abaxial conferindo aspecto ferruginoso à lesão (Ogawa et al., 1995; May-de Mio et al., 2004; Soto-Estrada et al., 2005).

Em casos de alta infestação em cultivares sensíveis, a doença provoca abscisão foliar precoce. A queda prematura das folhas resulta em menor acúmulo de carboidratos na planta e em redução da profundidade de dormência, o que provoca floração de outono não aproveitada, sujeita à perda por geadas e ao esgotamento do pomar, e prejudica os próximos ciclos produtivos e a vida útil do pomar (Rouse \& Sherman, 2002; May de Mio et al., 2004; Soto-Estrada \& Adaskaveg, 2004; Alves et al., 2008).

É importante a busca de estratégias complementares ao controle químico para evitar esta doença. Souza et al. (2007) verificaram efeito positivo da adubação nitrogenada na redução da severidade da doença nas folhas. Outra recomendação é o uso de cultivares resistentes ou menos suscetíveis à doença. Essas estratégias visam reduzir as aplicações de agrotóxicos nos pomares e evitar o surgimento de biótipos de patógenos tolerantes aos princípios ativos utilizados no controle da ferrugem, assim como minimizar os índices de contaminação ambiental. Assim, a avaliação criteriosa da reação do germoplasma de pessegueiro à ferrugem-da-folha é importante para auxiliar no desenvolvimento de cultivares com maior resistência ou tolerância a essa doença (Barbosa et al., 1994).

O objetivo deste trabalho foi identificar fontes de resistência à ferrugem-da-folha do pessegueiro.

\section{Material e Métodos}

As avaliações foram realizadas na coleção de genótipos de pessegueiro, situada na área experimental da Universidade Tecnológica Federal do Paraná - UTFPR, em Pato Branco, PR, a 26 $41^{\prime} \mathrm{S}, 56^{\circ} 07^{\prime} \mathrm{W}$ e
$750 \mathrm{~m}$ de altitude. O clima local é classificado, segundo Köppen, como Cfa (subtropical), com temperatura média no mês mais frio inferior a $18^{\circ} \mathrm{C}$ (mesotérmico). A temperatura média no mês mais quente está acima de $22^{\circ} \mathrm{C}$, com verões quentes e tendência de concentração de chuvas nos meses de verão, contudo sem estação seca definida.

A coleção está implantada em área de meia-encosta com exposição nordeste, linhas direcionadas predominantemente no sentido norte-sul, em conformidade com as curvas de nível. As plantas foram conduzidas em sistema de vaso, em espaçamento de $4 \times 5 \mathrm{~m}$ entre plantas e linhas. As práticas de manejo foram realizadas conforme recomendações gerais para a cultura, sem a utilização de produtos químicos para quebra da dormência (Raseira \& Centellas-Quezada, 2003).

As avaliações foram realizadas em três plantas (repetição) por genótipo. Para cada planta, foram avaliados cinco ramos do ano (unidades de observação), distribuídos uniformemente na porção mediana da planta, entre 1,5 e 1,8 m de altura do solo. As avaliações de intensidade de ferrugem-da-folha do pessegueiro foram realizadas em três ciclos produtivos (2004/2005, 2005/2006 e 2007/2008). Em 2006/2007, não houve avaliação, uma vez que a doença foi rigorosamente controlada por meio de aplicações frequentes de fungicidas, o que naquele momento tinha como finalidade a realização de estudos de resistência genética à bacteriose do pessegueiro (Xanthomonas arboricola pv. pruni). No ciclo 2004/2005, foram realizadas três avaliações de incidência e severidade de ferrugem-da-folha (15/1/2005, 14/2/2005 e 24/3/2005), em 17 genótipos: Conserva 985, Conserva 1205, Conserva 1153, Santa Áurea, Conserva 844, Conserva 977, Bonão, Conserva 1187, Conserva 1223, Conserva 655, Conserva 688, Conserva 1129, Conserva 871, Cascata 1063, Conserva 681, Olímpia e Atenas. No ciclo 2005/2006, foi realizada apenas uma avaliação de severidade (23/2/2006) em razão da baixa pressão da doença, no início do ciclo. Nessa ocasião, 29 genótipos foram avaliados: Conserva 1127, Conserva 1125, Conserva 1186, Rubimel, Cascata 1055, Cascata 1065, Tropic Snow, Cascata 3962, Cascata 967, Cascata 1070, Tropic Beauty, Cascata 834 e os 17 genótipos avaliados no ciclo anterior (citados acima). No ciclo 2007/2008, realizou-se a avaliação de incidência, da severidade e da desfolha em 28/1/2008, nos 29 genótipos, anteriormente citados, com a 
inclusão do Conserva 803. Além disso, avaliou-se a evolução mensal da desfolha, de novembro de 2007 a fevereiro de 2008 em 12 genótipos: Conserva 844, Conserva 1153, Conserva 803, Conserva 1125, Tropic Beauty, Atenas, Conserva 681, Conserva 977, Conserva 871, Cascata 587, Olímpia, Cascata 1063.

Os percentuais de incidência, severidade e desfolha, para cada repetição (planta), foram obtidos a partir das médias dos ramos. Para quantificar a severidade, utilizou-se a escala diagramática proposta por Rodrigues et al. (2008), contudo, a presença de folhas com severidade superior às descritas na escala foi frequente. Valores encontrados acima da escala foram quantificados conforme a percepção do avaliador.

Os resultados foram submetidos à análise de variância, e as médias dos genótipos, dentro de cada ano, foram comparadas pelo teste de Scott-Knott, a 5\% de probabilidade. Os dados expressos em percentuais foram transformados em arco seno $(\mathrm{x} / 100)^{0,5}$. Foram realizadas correlações de Pearson entre incidência, severidade e desfolha do ciclo 2007/2008. Os dados de severidade, incidência e desfolha de 28/1/2008 e os severidade do ciclo 2005/2006 foram submetidos à análise multivariada, tendo-se adotado a medida de dissimilaridade de Mahalanobis $\left(\mathrm{D}^{2}\right)$, a partir de médias padronizadas, para formação dos grupos. Com base na matriz de dissimilaridade gerada, foi aplicado o método de agrupamento de Tocher e construído dendrograma pelo método do agrupamento da distância média (UPGMA) (Johnson \& Wichern, 1998), em que se considerou a maior distância (obtida pela $\mathrm{D}^{2}$ ) como $100 \%$ de distância. Os agrupamentos foram delimitados pela análise visual do dendrograma, tendo-se considerado a distância genética de 50\% para a formação dos grupos e, no caso da formação de subgrupos, considerou-se $25 \%$ da distância genética. A importância relativa dos caracteres avaliados, para a estimativa da dissimilaridade genética, foi obtida por meio da participação dos componentes da $\mathrm{D}^{2}$, relativos a cada caráter, no total da dissimilaridade observada (Singh, 1981). Foi também realizada a análise de variáveis canônicas, a fim de se obter a dispersão gráfica em espaço bidimensional dos genótipos estudados, quanto às variáveis epidemiológicas relacionadas à ferrugem-da-folha em pessegueiro.

Com base nas avaliações de severidade, incidência e desfolha, os genótipos foram agrupados em três grupos distintos: suscetíveis, moderadamente suscetíveis e resistentes. Dentro de cada grupo, foram selecionados quatro genótipos representativos para a contagem do número de lesões por folha. Desses genótipos selecionados, coletaram-se, em 3/2/2008, cinco ramos do ano de cada planta (repetição), e de cada ramo foram retirados três folhas na porção intermediária, no total de 15 folhas por planta e 45 por genótipo. Foi quantificado o número de lesões ocasionadas pela ferrugem em cada folha, com auxílio de um estereomicroscópio com aumento de 20 vezes. Consideraram-se lesões as manchas visualizadas na face superior da folha, independentemente do número de pústulas existente em cada lesão. Calcularam-se os coeficientes de correlação de Pearson entre o número de lesões por folha e a severidade, incidência, desfolha do ciclo $2007 / 2008$ pelo teste $\mathrm{t}$ a $1 \%$ de probabilidade. Todas as análises estatísticas foram realizadas com o auxílio do programa Genes (Cruz, 2006), e os dados climáticos do período de avaliação estão na Tabela 1 .

\section{Resultados e Discussão}

Observou-se, nos três ciclos produtivos avaliados, reação diferenciada entre os genótipos quanto à manifestação da ferrugem-da-folha, o que evidencia a existência de diferentes níveis de resistência entre esses genótipos. A existência de variabilidade quanto à resistência à ferrugem-da-folha em pessegueiro também foi observada em outros trabalhos (Barbosa et al., 1994; Centellas-Quezada, 2000; Rouse \& Shermann, 2002; Citadin et al., 2005).

$\mathrm{Na}$ primeira avaliação do ciclo 2004/2005 (15/1/2005), não foi constatada diferença significativa entre os genótipos quanto aos percentuais de severidade e incidência de ferrugem-da-folha (Tabela 2). Entretanto, nas demais avaliações $(14 / 2 / 2005$ e 24/3/2005), observou-se que os genótipos Conserva 985, Conserva 977, Santa Áurea, Conserva 1153, Conserva 1187, Conserva 1205 e Conserva 844 sempre se mantiveram agrupados como os mais sensíveis à ferrugem-da-folha, enquanto Cascata 1063, Atenas e Olímpia, apresentaram os menores percentuais de severidade e incidência da doença. Na avaliação realizada em 24/3/2005, os genótipos sensíveis apresentavam sintomas de ferrugem na totalidade das folhas e em alta severidade, próxima dos $20 \%$, enquanto os genótipos de maior resistência apresentavam níveis de severidade inferiores a $2 \%$. 
Verificou-se que o maior volume de precipitação e o maior número de dias com chuvas ocorreram no ciclo de 2005/2006 (Tabela 1). Nesse ciclo, observaram-se

Tabela 1. Temperatura média $\left({ }^{\circ} \mathrm{C}\right)$, umidade relativa média $(\%)$, precipitação mensal $(\mathrm{mm})$ e número de dias com chuva, durante a condução do experimento. (Dados cedidos pelo Instituto Agronômico do Paraná).

\begin{tabular}{lccccccc}
\hline Dados climáticos & Set. & Out. & Nov. & Dez. & Jan. & Fev. & Mar. \\
\hline Temperatura $\left({ }^{\circ} \mathrm{C}\right)$ & 19,5 & 18,7 & 19,8 & 21,6 & 22,9 & 23 & 22,6 \\
UR (\%) & 67,2 & 65,4 & 71,4 & 78,1 & 78,1 & 70,4 & 64,1 \\
Precipitação (mm) & 108,6 & 357,3 & 267,8 & 109,8 & 163,7 & 28,6 & 58,1 \\
Dias com chuva & 7 & 8 & 11 & 10 & 9 & 5 & 3 \\
\hline & \multicolumn{7}{c}{$2005 / 2006$} \\
Temperatura $\left({ }^{\circ} \mathrm{C}\right)$ & 14,6 & 19,9 & 21,6 & 22,2 & 22,9 & 22,3 & 21,8 \\
UR (\%) & 74,8 & 79,1 & 63,2 & 65,7 & 75,1 & 74,8 & 76,6 \\
Precipitação (mm) & 273,1 & 408,5 & 86,4 & 22,1 & 238,8 & 53,2 & 129,3 \\
Dias com chuva & 14 & 17 & 6 & 4 & 19 & 9 & 14 \\
\hline & \multicolumn{7}{c}{$2007 / 2008$} \\
Temperatura $\left({ }^{\circ} \mathrm{C}\right)$ & 20,7 & 20,6 & 20,4 & 22,5 & 22 & 22 & 21,3 \\
UR (\%) & 66,7 & 70,9 & 62,1 & 69,7 & 74 & 73,2 & 73,1 \\
Precipitação (mm) & 31 & 172,0 & 241,8 & 190,3 & 90,4 & 133,9 & 129,8 \\
Dias com chuva & 5 & 11 & 9 & 11 & 11 & 10 & 7 \\
\hline
\end{tabular}

também a maior severidade da doença, em genótipos sensíveis, e a maior amplitude de severidade de ferrugem entre os genótipos moderadamente sensíveis e resistentes (Tabela 2). Também nesse ciclo, os genótipos que apresentaram menor severidade foram Olímpia, Cascata 1063, Atenas, Conserva 871, Cascata 1070, Conserva 967, Conserva 1205, Conserva 655, Conserva 688, Cascata 3962, Conserva 681, Conserva 844 e Santa Áurea. A severidade atingiu valores máximos no genótipo Conserva $1127(23,33 \%)$, porém, nas mesmas condições, alguns genótipos manifestaram severidade inferior a 1\% (Conserva 871, Cascata 1070, Atenas, Cascata 1063 e Olímpia). No ciclo 2007/2008, as cultivares Olímpia e Tropic Snow e as seleções, Cascata 3962, Cascata 1063, Conserva 985, Cascata 1070, Conserva 688 e Cascata 587 foram as mais resistentes, apresentando severidade menor que $1 \%$, incidência menor que $80 \%$, desfolha inferior ou próximo a $27 \%$ (Tabela 2). Na análise conjunta dos três anos $(2005,2006,2008)$, observou-se que os genótipos

Tabela 2. Incidência, severidade, desfolha e número de lesões por folha, causadas por ferrugem-da-folha (Tranzschelia discolor), em genótipos de pessegueiro nos ciclos produtivos e respectivas datas de avaliação ${ }^{(1)}$.

\begin{tabular}{|c|c|c|c|c|c|c|c|c|c|c|c|}
\hline \multirow[t]{2}{*}{ Genótipos } & \multicolumn{4}{|c|}{$\begin{array}{c}\text { Incidência } \\
(\%)\end{array}$} & \multicolumn{5}{|c|}{$\begin{array}{c}\text { Severidade } \\
(\%)\end{array}$} & \multirow{2}{*}{$\begin{array}{c}\begin{array}{c}\text { Desfolha } \\
(\%)\end{array} \\
28 / 1 / 2008\end{array}$} & \multirow{2}{*}{$\begin{array}{l}\mathrm{N}^{\mathrm{o}} \text { de lesões } \\
\text { por folha } \\
28 / 1 / 2008\end{array}$} \\
\hline & $15 / 1 / 2005$ & $14 / 2 / 2005$ & $24 / 3 / 2005$ & $28 / 1 / 2008$ & $15 / 1 / 2005$ & $14 / 2 / 2005$ & $24 / 3 / 2005$ & $23 / 2 / 2006$ & $28 / 1 / 2008$ & & \\
\hline Conserva 803 & - & - & - & $98,54 \mathrm{a}$ & - & - & - & - & $4,78 \mathrm{a}$ & $53,51 b$ & $176,13 a$ \\
\hline Conserva 1153 & $1,19 \mathrm{a}$ & $99,58 \mathrm{a}$ & $100,00 \mathrm{a}$ & $97,45 \mathrm{a}$ & $0,05 \mathrm{a}$ & $8,67 \mathrm{a}$ & $20,00 \mathrm{a}$ & $11,17 \mathrm{~b}$ & $3,95 \mathrm{a}$ & $50,97 b$ & $190,00 \mathrm{a}$ \\
\hline Conserva 1125 & - & - & - & $100,0 \mathrm{a}$ & - & - & - & $13,83 b$ & $3,79 a$ & $59,33 a$ & $154,07 \mathrm{a}$ \\
\hline Rubimel & - & - & - & $95,23 \mathrm{a}$ & - & - & - & $7,92 \mathrm{~b}$ & $3,62 \mathrm{a}$ & $57,20 \mathrm{a}$ & - \\
\hline Conserva 1223 & $0,00 \mathrm{a}$ & $82,67 a$ & $99,17 \mathrm{a}$ & $100,0 \mathrm{a}$ & $0,00 \mathrm{a}$ & $6,58 \mathrm{a}$ & $6,93 \mathrm{c}$ & $9,58 \mathrm{~b}$ & $2,73 b$ & $27,42 \mathrm{c}$ & - \\
\hline Conserva 844 & $0,67 \mathrm{a}$ & $83,75 a$ & $100,00 \mathrm{a}$ & $99,62 \mathrm{a}$ & $0,13 \mathrm{a}$ & $5,83 \mathrm{a}$ & $18,22 \mathrm{a}$ & $1,75 \mathrm{~d}$ & $2,60 \mathrm{~b}$ & $41,13 b$ & $208,53 a$ \\
\hline Conserva 1127 & - & - & - & $99,33 \mathrm{a}$ & - & - & - & $23,33 a$ & $2,43 b$ & $59,73 a$ & - \\
\hline Tropic Beauty & - & - & - & $94,60 \mathrm{a}$ & - & - & - & $3,50 \mathrm{c}$ & $2,17 b$ & $19,51 \mathrm{c}$ & $131,53 b$ \\
\hline Santa Áurea & $0,34 \mathrm{a}$ & $93,33 a$ & $100,00 \mathrm{a}$ & $97,79 \mathrm{a}$ & $0,23 \mathrm{a}$ & $6,75 \mathrm{a}$ & $20,00 \mathrm{a}$ & $1,75 \mathrm{~d}$ & $2,06 \mathrm{~b}$ & $11,84 \mathrm{~d}$ & - \\
\hline Conserva 655 & $0,08 \mathrm{a}$ & $52,50 \mathrm{~b}$ & $100,00 \mathrm{a}$ & $94,03 \mathrm{a}$ & $0,05 \mathrm{a}$ & $1,58 \mathrm{~b}$ & $12,54 \mathrm{~b}$ & $1,25 \mathrm{~d}$ & $1,78 \mathrm{c}$ & $15,13 \mathrm{c}$ & - \\
\hline Conserva 1187 & $1,56 \mathrm{a}$ & $92,08 \mathrm{a}$ & $100,00 \mathrm{a}$ & $94,56 \mathrm{a}$ & $0,13 \mathrm{a}$ & $3,42 \mathrm{a}$ & $19,91 \mathrm{a}$ & $4,00 \mathrm{c}$ & $1,76 \mathrm{c}$ & $17,60 \mathrm{c}$ & - \\
\hline Conserva 977 & $0,18 \mathrm{a}$ & $91,25 \mathrm{a}$ & $100,00 \mathrm{a}$ & $96,75 a$ & $0,04 \mathrm{a}$ & $4,50 \mathrm{a}$ & $20,01 \mathrm{a}$ & $4,42 \mathrm{c}$ & $1,44 \mathrm{c}$ & $21,72 \mathrm{c}$ & $79,60 \mathrm{~b}$ \\
\hline Bonão & $0,11 \mathrm{a}$ & $92,50 \mathrm{a}$ & $100,00 \mathrm{a}$ & $93,22 \mathrm{a}$ & $0,03 \mathrm{a}$ & $6,42 \mathrm{a}$ & $15,78 \mathrm{~b}$ & $3,58 \mathrm{c}$ & $1,41 \mathrm{c}$ & $36,89 \mathrm{~b}$ & - \\
\hline Atenas & $0,30 \mathrm{a}$ & $32,50 \mathrm{c}$ & $21,67 d$ & $95,07 \mathrm{a}$ & $0,09 \mathrm{a}$ & $0,83 b$ & $1,00 \mathrm{~d}$ & $0,33 d$ & $1,37 \mathrm{c}$ & $19,85 \mathrm{c}$ & $108,33 b$ \\
\hline Cascata 1055 & - & - & - & $94,18 \mathrm{a}$ & - & - & - & $7,08 \mathrm{~b}$ & $1,30 \mathrm{c}$ & $17,13 \mathrm{c}$ & - \\
\hline Conserva 1186 & - & - & & $97,28 \mathrm{a}$ & - & - & - & $8,92 b$ & $1,28 \mathrm{c}$ & $26,89 \mathrm{c}$ & - \\
\hline Conserva 681 & $0,00 \mathrm{a}$ & $1,67 \mathrm{~d}$ & $94,44 b$ & $100,0 \mathrm{a}$ & $0,00 \mathrm{a}$ & $0,08 b$ & $3,89 \mathrm{c}$ & $1,33 \mathrm{~d}$ & $1,23 \mathrm{c}$ & $15,46 \mathrm{c}$ & $100,20 b$ \\
\hline Conserva 967 & - & - & - & $68,58 \mathrm{~b}$ & - & - & - & $1,17 \mathrm{~d}$ & $1,08 \mathrm{c}$ & $6,15 \mathrm{~d}$ & - \\
\hline Conserva 1205 & $12,76 \mathrm{a}$ & $97,08 \mathrm{a}$ & $100,00 \mathrm{a}$ & $91,91 \mathrm{a}$ & $0,29 \mathrm{a}$ & $8,00 \mathrm{a}$ & $19,80 \mathrm{a}$ & $1,17 \mathrm{~d}$ & $0,96 \mathrm{c}$ & $12,20 \mathrm{~d}$ & - \\
\hline Tropic Snow & - & - & - & $79,18 \mathrm{~b}$ & - & - & - & $4,58 \mathrm{c}$ & $0,75 \mathrm{~d}$ & $16,05 \mathrm{c}$ & - \\
\hline Conserva 1129 & $0,00 \mathrm{a}$ & $63,29 b$ & - & $93,20 \mathrm{a}$ & $0,00 \mathrm{a}$ & $0,85 b$ & $13,60 \mathrm{~b}$ & $10,07 b$ & $0,65 \mathrm{~d}$ & $5,93 d$ & - \\
\hline Cascata 587 & - & - & - & $78,54 \mathrm{~b}$ & - & - & - & $5,50 \mathrm{~b}$ & $0,65 \mathrm{~d}$ & $6,60 \mathrm{~d}$ & $18,47 \mathrm{c}$ \\
\hline Conserva 688 & $0,00 \mathrm{a}$ & $27,92 \mathrm{c}$ & $92,00 \mathrm{~b}$ & $78,78 \mathrm{~b}$ & $0,00 \mathrm{a}$ & $1,92 b$ & $10,44 b$ & $1,25 \mathrm{~d}$ & $0,65 \mathrm{~d}$ & $12,33 d$ & - \\
\hline Conserva 871 & $0,00 \mathrm{a}$ & $33,50 \mathrm{c}$ & $97,00 \mathrm{~b}$ & $87,84 \mathrm{a}$ & $0,00 \mathrm{a}$ & $1,25 b$ & $4,87 \mathrm{c}$ & $0,75 \mathrm{~d}$ & $0,58 \mathrm{~d}$ & $9,11 \mathrm{~d}$ & $36,73 \mathrm{c}$ \\
\hline Cascata 1070 & - & - & - & $71,79 \mathrm{~b}$ & - & - & - & $0,75 \mathrm{~d}$ & $0,53 \mathrm{~d}$ & $26,14 \mathrm{c}$ & - \\
\hline Conserva 985 & $2,37 \mathrm{a}$ & $95,00 \mathrm{a}$ & $100,00 \mathrm{a}$ & $61,79 \mathrm{~b}$ & $0,09 \mathrm{a}$ & $3,98 \mathrm{a}$ & $21,39 \mathrm{a}$ & $3,17 \mathrm{c}$ & $0,47 \mathrm{~d}$ & $4,64 c$ & - \\
\hline Cascata 1063 & $0,00 \mathrm{a}$ & $29,33 c$ & $34,00 \mathrm{~d}$ & $75,72 b$ & $0,00 \mathrm{a}$ & $1,67 b$ & $1,80 \mathrm{~d}$ & $0,25 \mathrm{~d}$ & $0,45 \mathrm{~d}$ & $20,29 \mathrm{c}$ & $0,80 \mathrm{~d}$ \\
\hline Cascata 3962 & - & - & - & $67,00 \mathrm{~b}$ & - & - & - & $1,25 \mathrm{~d}$ & $0,41 \mathrm{~d}$ & $17,50 \mathrm{c}$ & - \\
\hline Cascata 1065 & - & - & & $96,58 \mathrm{a}$ & - & - & - & $4,83 \mathrm{c}$ & $0,31 \mathrm{~d}$ & $13,17 d$ & - \\
\hline Olímpia & $0,00 \mathrm{a}$ & $44,33 b$ & $62,67 \mathrm{c}$ & $57,84 \mathrm{~b}$ & $0,00 \mathrm{a}$ & $0,83 \mathrm{~b}$ & $1,08 \mathrm{~d}$ & $0,08 \mathrm{~d}$ & $0,26 \mathrm{~d}$ & $9,05 \mathrm{~d}$ & $5,27 \mathrm{~d}$ \\
\hline CV (\%) & 27,5 & 17,07 & 7,17 & 10,93 & 48,16 & 28,13 & 15,83 & 19,52 & 19,52 & 16,17 & 20,21 \\
\hline
\end{tabular}

${ }^{(1)}$ Médias seguidas de letras iguais, não diferem entre si pelo teste de Scott-Knott, a 5\% de probabilidade. (-)Não avaliado no ciclo. 
Conserva1153, Conserva1125, Rubimel, Conserva 1127 e Conserva 1223 foram os mais suscetíveis, enquanto Olímpia, Cascata 1063, Conserva 871 e Cascata 3962 foram os mais resistentes.

Foram constatadas correlações significativas, a $1 \%$ de probabilidade, entre todos os componentes epidemiológicos utilizados para a análise multivariada, o que demonstra que esses podem ser adotados como parâmetros para avaliação de genótipos quanto à reação à ferrugem-da-folha. A severidade $\mathrm{x}$ incidência apresentou coeficientes de correlação de Pearson $\mathrm{r}=0,80^{* *}$, seguidos de severidade $\mathrm{x}$ desfolha $\left(\mathrm{r}=0,79^{* *}\right)$ e da incidência $\mathrm{x}$ desfolha $\left(\mathrm{r}=0,59^{* *}\right)$. $\mathrm{Na}$ análise multivariada, verificou-se que a severidade $\mathrm{e}$ a incidência, independentemente do ciclo de avaliação, foram as variáveis epidemiológicas mais eficientes na distinção de diferenças quanto ao nível de resistência dos genótipos à ferrugem. Juntas, essas duas variáveis contribuíram com $73,05 \%$ da dissimilaridade total (Tabela 3). Para Yorinori \& Kiihl (2001) e Vale et al. (2001), a severidade pode ser uma boa variável para diferenciar níveis de resistência quantitativa. Chaves et al. (2004) sugerem que essas avaliações podem ser realizadas diversas vezes, durante o ciclo vegetativo da planta, ou em uma única vez no final do ciclo, e que são eficientes em detectar diferenças em condições de campo.

De acordo com a análise de agrupamento, levando-se em conta os caracteres epidemiológicos avaliados, foi possível visualizar no dendrograma (Figura 1) a formação de três grupos distintos quanto à sensibilidade à ferrugem-da-folha, tendose considerado $50 \%$ da distância generalizada de Mahalanobis. Os grupos II e III foram caracterizados pelo agrupamento de genótipos suscetíveis à ferrugem. O grupo III foi representado apenas pelo genótipo Conserva 1127, que se mostrou extremamente suscetível à doença, nos ciclos de avaliação. Assim,

Tabela 3. Contribuição relativa dos componentes epidemiológicos para a dissimilaridade apresentada entre 30 genótipos de pessegueiro quanto ao grau de resistência à ferrugem-da-folha (Tranzschelia discolor), com base na estatística de Singh (1981), no ciclo 2008.

\begin{tabular}{lccc}
\hline Componente & \multicolumn{3}{c}{ Dissimilaridade genética } \\
\cline { 2 - 4 } & Autovalores & Percentagem & Acumulada (\%) \\
\hline Severidade & $4.794,93$ & 39,66 & 39,66 \\
Incidência & $4.037,58$ & 33,39 & 73,05 \\
Desfolha & $1.727,01$ & 14,29 & 87,34 \\
\hline
\end{tabular}

deve-se evitar a sua utilização em cruzamentos que visam à obtenção de genótipos para ambientes de alta ocorrência da doença.

Agruparam-se no grupo II os genótipos Bonão, Conserva 844, Conserva 1125, Conserva 1153, Conserva 803 e Rubimel, que mostraram grande suscetibilidade à doença. Em média, os genótipos deste grupo apresentaram severidade de $8,06 \%$ (no ciclo $2005 / 2006$ ) e $3,35,97,34$ e $49,83 \%$ para severidade, incidência e desfolha, respectivamente, no ciclo 2007/2008.

Agruparam-se no grupo I genótipos que tiveram suscetibilidade de moderada a resistente, em cinco subgrupos distintos, considerando-se $25 \%$ da distância generalizada de Mahalanobis. Nesse grupo, destacouse o subgrupo II (Cascata 1063, Cascata 1070, Conserva 688, Cascata 3962 e Olímpia), em que se agruparam os genótipos mais resistentes, com $0,71 \%$ de severidade média para o ciclo 2005/2006, e 0,46, 70,22 e $17,06 \%$ de severidade, incidência e desfolha, respectivamente, no ciclo 2007/2008. A obtenção de agrupamentos e subagrupamentos com semelhanças epidemiológicas, dentro do grupo, e distintas entre os grupos, mostra que esse tipo de análise é capaz de distinguir e agrupar, com eficiência, os genótipos quanto ao grau de sensibilidade à doença, o que é útil aos programas de melhoramento de pessegueiro.

A análise de variáveis canônicas (VC) demonstrou que as duas primeiras variáveis (VC1 e VC2) são responsáveis por aproximadamente $82 \%$ da variância total (Tabela 4), e é possível explicar de maneira satisfatória a variabilidade manifestada quanto à ferrugem-da-folha entre os genótipos, o que permite interpretar o fenômeno com bastante simplificação, e representá-las em gráfico de dispersão bidimensional (Figura 2). Para a plotagem das variáveis canônicas em gráfico bidimensional é necessário que as duas variáveis canônicas envolvam mais de $80 \%$ da variância total dos genótipos, e que cada variável canônica seja uma combinação linear das variáveis originais analisadas (Cruz, 2006). Observou-se que os agrupamentos formados na dispersão bidimensional se assemelharam aos formados no dendrograma e, de acordo com essa análise, os genótipos mais suscetíveis foram Conserva 1127 (22), Conserva 803 (7), Conserva 1125 (21), Bonão (20), Conserva 1153 (24) e Rubimel (11), que se localizaram mais distantes do genótipo Olímpia (10), que foi de maior resistência à doença. 
Outro parâmetro para mensurar a resistência quantitativa seria o número de pústulas por folha (Centellas-Quezada, 2000), que pode ser considerado como bom parâmetro para a seleção de genótipos resistentes. Contudo, esse método requer mão de obra especializada que, em regiões com alta infestação da doença, se restringe ao início da epidemia, ou a situações de ambiente controlado, quando os genótipos forem inoculados com baixa pressão de inóculo. Para dar maior agilidade e flexibilidade às avaliações, buscou-se quantificar o número de lesões por folha,

Tabela 4. Variâncias (autovalores), variâncias percentuais e variâncias acumuladas das variáveis canônicas, para estimar a dissimilaridade quanto à resistência genética à ferrugemda-folha (Tranzschelia discolor), em 30 genótipos de pessegueiro, no ciclo 2007/2008.

\begin{tabular}{lccc}
\hline $\begin{array}{l}\text { Variável } \\
\text { canônica }\end{array}$ & $\begin{array}{c}\text { Variância } \\
\text { (autovalores) }\end{array}$ & $\begin{array}{c}\text { Variância } \\
\text { percentuais }\end{array}$ & $\begin{array}{c}\text { Variância } \\
\text { acumulada }\end{array}$ \\
\hline VC1 & 7,92 & 57,06 & 57,06 \\
VC2 & 3,42 & 24,64 & 81,71 \\
VC3 & 1,46 & 10,52 & 92,23 \\
VC4 & 1,07 & 7,77 & 100,00 \\
\hline
\end{tabular}

como mais um parâmetro que pode ser utilizado na seleção de genótipos de pessegueiro resistentes à ferrugem-da-folha.

Assim, foi quantificado o número de lesões por folha de 12 genótipos, classificados de acordo com o grau de resistência à ferrugem, tendo-se considerado os agrupamentos formados pela análise multivariada (Figuras 1 e 2) e pelas análises de incidência, severidade e desfolha nos três ciclos avaliados (Tabela 2). Os genótipos foram separados em três grupos, com quatro genótipos por grupo considerados como suscetíveis (Conserva 844, Conserva 1153, Conserva 803 e Conserva 1125), moderadamente suscetíveis (Tropic Beauty, Atenas, Conserva 681 e Conserva 977) e resistentes (Conserva 871, Cascata 587, Olímpia e Cascata 1063) (Tabela 2). Os coeficientes de correlação de Pearson entre número de lesões por folha e severidade, incidência e desfolha foram $\mathrm{r}=0,89 * *$, $\mathrm{r}=0,91^{* *}$ e $\mathrm{r}=0,74^{* *}$, respectivamente. A contagem do número de lesões por folha no processo de seleção e a classificação de genótipos de pessegueiros quanto à ferrugem-da-folha foi eficiente, pois se correlacionou

Conserva 1187
Tropic Beauty

Tropic Beauty

Conserva 655

Conserva 871

Conserva 1205

Atenas

Conserva 681

Cascata 1063

Cascata 1070

Conserva 688

Cascata 3962

Olimpia

Cascata 587

Conserva 985

Cascata 967

Cascata 1055

Cascata 1065

Conserva 977

Tropic Snow

Conserva 1186

Conserva 1223

Conserva 1129

Rubimel

Conserva 115

Conserva 803

Conserva 1125

Conserva 844

Bonão

Conserva 1127

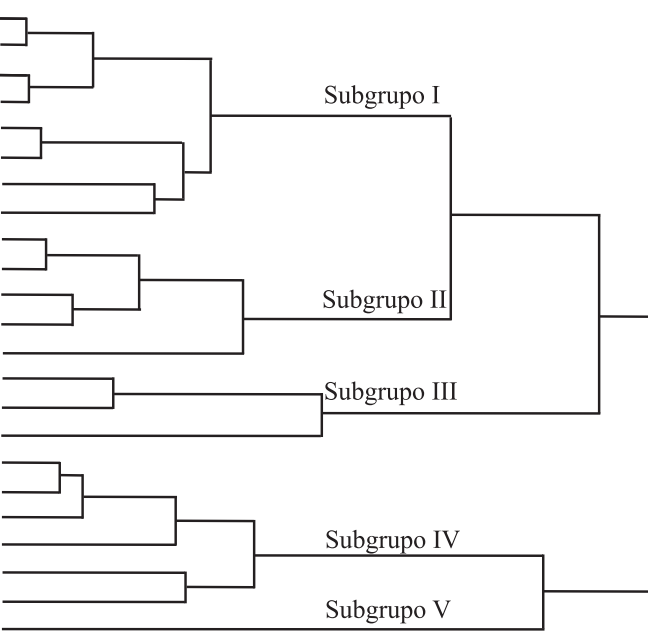

Grupo I

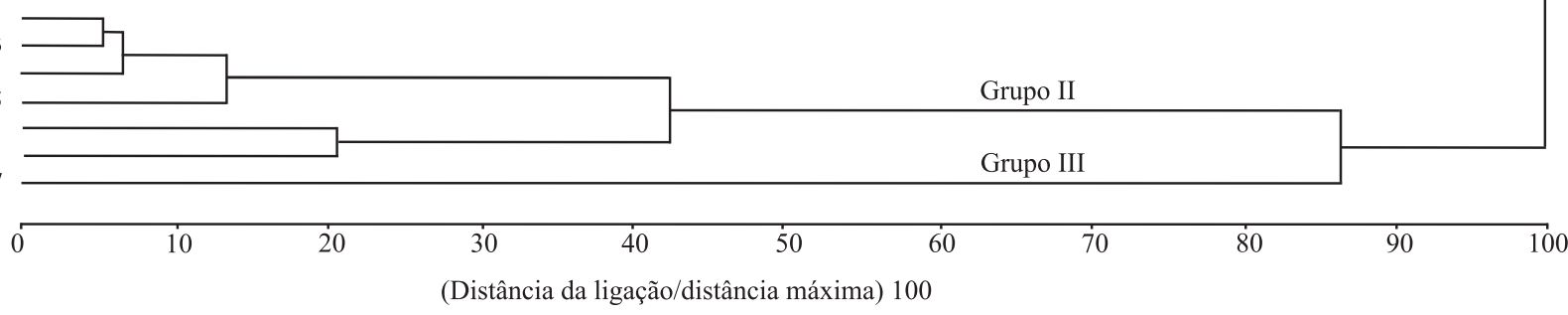

Figura 1. Dendrograma representativo da dissimilaridade genética entre 30 genótipos de pessegueiro, obtido pelo método UPGMA, com base em quatro características epidemiológicas (incidência, severidade, desfolha do ciclo 2007/2008 e severidade do ciclo 2005/2006), relacionadas à ferrugem-da-folha (Tranzschelia discolor), com uso da distância generalizada de Mahalanobis. 
significativamente a $1 \%$ de probabilidade, com todas as demais variáveis epidemiológicas avaliadas. Os genótipos considerados resistentes apresentaram, além de menor número de lesões por folha, menor severidade, incidência, desfolha final, destacando-se a cultivar Olímpia e o genótipo Cascata 1063 (Tabela 2). Esse procedimento foi realizado com intuito de identificar a existência de diferenças epidemiológicas entre genótipos sensíveis e resistentes, principalmente quanto ao número de lesões por folha, com a finalidade de utilização futura dessa técnica, em programas de melhoramento de pessegueiro como indicadora de fontes de resistência.

A evolução da desfolha foi analisada de acordo com os grupos de resistência, formados pelos genótipos utilizados na contagem de lesões (Figura 3), tendo-se observado que, até 15 de janeiro de 2008, praticamente, não houve desfolha nos genótipos resistentes, enquanto nos suscetíveis os percentuais médios de desfolha foram superiores a $35 \%$. O grupo dos genótipos

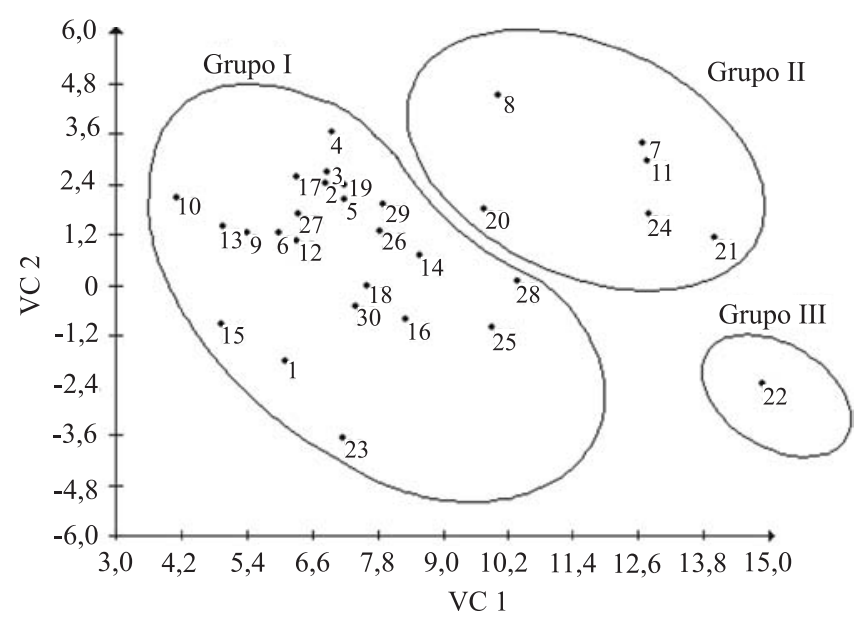

Figura 2. Dispersão gráfica dos escores da primeira (VC1) e da segunda (VC2) variável canônica e classificação dos genótipos de pessegueiro, em três grupos distintos de resistência à ferrugem-da-folha (Tranzschelia discolor), com base na avaliação do ciclo 2007/2008: 1, Cascata 587; 2, Santa Áurea; 3, Conserva 655; 4, Atenas; 5, Conserva 681; 6, Conserva 688; 7, Conserva 803; 8, Conserva 844; 9, Conserva 871; 10, Olímpia; 11, Rubimel; 12, Cascata 834; 13, Cascata 967; 14, Conserva 977; 15, Conserva 985; 16, Cascata 1055; 17, Cascata 1063; 18, Cascata 1065; 19, Cascata 1070; 20, Bonão; 21, Conserva 1125; 22, Conserva 1127; 23 , Conserva 1129; 24, Conserva 1153; 25, Conserva 1186; 26, Conserva 1187; 27, Conserva 1205; 28, Conserva 1223; 29, Tropic Beauty; 30, Tropic Snow. moderadamente suscetíveis teve comportamento semelhante à média geral do experimento. Portanto, os genótipos resistentes apresentaram evolução lenta da desfolha, quando comparados aos demais. Esses resultados estão de acordo com os obtidos por Rouse \& Sherman (2002), que observaram, em genótipos resistentes, quantidade reduzida de pústulas e lesões de ferrugem-da-folha, expressão tardia dos sintomas de infecção da doença e desfolhamento em relação a genótipos de pessegueiro suscetíveis à ferrugem.

O tipo de resistência observado nesses genótipos é predominantemente horizontal, uma vez que não foram encontrados genótipos imunes. Segundo Camargo \& Bergamim Filho (1995), a resistência horizontal possuí características parciais e quantitativas, ou seja, em cultivares com resistência horizontal, a eficiência de infecção é menor do que em uma cultivar suscetível. As lesões crescem mais lentamente, os esporos são produzidos mais tardiamente e em menor quantidade, o que afeta a taxa de desenvolvimento da doença e culmina na redução dos danos causados pela doença.

Verificou-se que a presença do genótipo Convênio como parental nas últimas três gerações, auxiliou na obtenção de resistência, como no caso das seleções Conserva 871 [Lord (Abóbora $\mathrm{x}$ Taquari Precoce) PL x Diamante (Convênio PL x

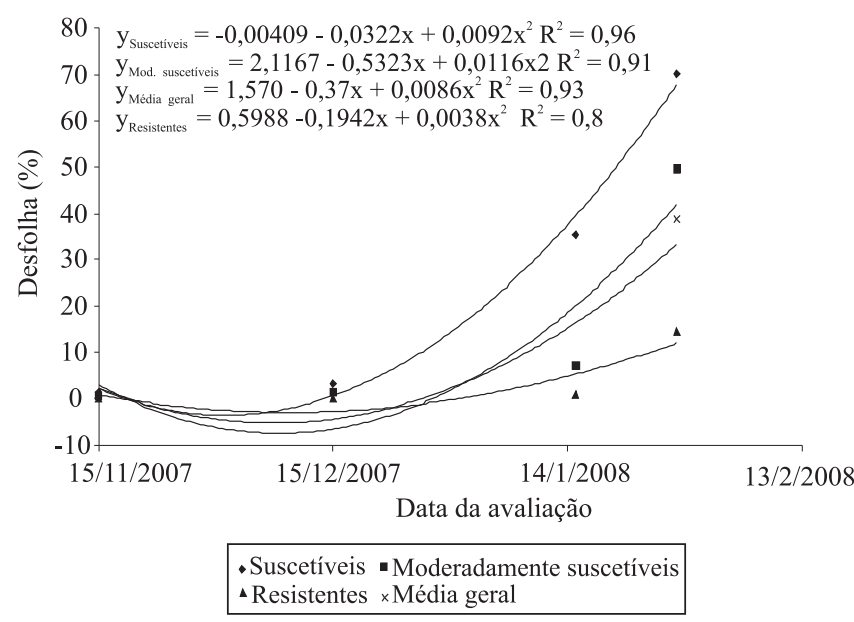

Figura 3. Evolução da desfolha causada por ferrugemda-folha (Tranzschelia discolor), de acordo com o nível de sensibilidade dos genótipos de pessegueiro avaliados. Suscetíveis: Conserva 844, Conserva 1153, Conserva 803 e Conserva 1125. Moderadamente suscetíveis: Tropic Beauty, Atenas, Conserva 681 e Conserva 977. Resistentes: Conserva 871, Cascata 587, Olímpia e Cascata 1063. 
Pelotas 77)] e Conserva 1129 (Conserva 536 PL $\mathrm{x}$ Diamante). Esse genótipo foi classificado como resistente por Centellas-Quezada (2000) e teve eficiência na transmissão de resistência a ferrugem da folha, obtendo-se progênies classificadas como moderadamente resistentes, quando em cruzamentos com genitor sensível a doença. Entretanto, não há garantia de que essa resistência seja expressa, pois em alguns casos, o cruzamento de um genótipo resistente (R) ou moderadamente resistente (MR) com suscetível ( $\mathrm{S}$ ), resultou em progênies moderadamente suscetíveis e suscetíveis, indicando que o modo de herança para a ferrugem da folha pode ser recessivo, conforme sugerido por Rouse \& Shermam (2002). Exemplos desse comportamento são as seleções Conserva 1125 [Conserva 594 PL (MR) x Pepita (S)] e Conserva 1153 [Conserva 677 (MR) x Granada (S)], que apesar de apresentar um genitor com moderada resistência à ferrugem, apresentam elevada sensibilidade ao patógeno, sendo classificados como suscetíveis.

$\mathrm{O}$ uso de genótipos com resistência parcial à ferrugem-da-folha pode ser útil na redução do número de aplicações de fungicidas em pomares de pessegueiro. Em geral, os genótipos Olímpia e Cascata 1063 apresentaram comportamento constante nos quatro anos de avaliação, com resistência à ferrugem, os quais podem ser utilizados como genitores em futuras hibridações controladas, visando esse objetivo.

\section{Conclusões}

1. $\bigcirc$ genótipos de pessegueiro Olímpia e Cascata 1063 apresentam níveis aceitáveis de resistência à ferrugem-da-folha (Tranzschelia discolor).

2. Não há genótipos totalmente imunes à ferrugem-da-folha, mas sim eficiência de infecção diferenciada entre os genótipos estudados, o que sugere que a resistência encontrada seja do tipo horizontal.

3. O número de lesões por folha pode ser usado para classificar genótipos de pessegueiro quanto à reação à ferrugem-da-folha.

\section{Agradecimentos}

À Embrapa Clima Temperado, pelo fornecimento do germoplasma de pessegueiro.

\section{Referências}

ALVES, G.; MAY-DE MIO, L.L. Efeito da desfolha causada pela ferrugem na floração e produtividade do pessegueiro. Revista Brasileira de Fruticultura, v.30, p.907-912, 2008.

ALVES, G.; MAY-DE MIO, L.L.; ZANETTE, F.; OLIVEIRA, M.C. Ferrugem do pessegueiro e seu efeito na desfolha e na concentração de carboidratos em ramos e gemas. Tropical Plant Pathology, v.33, p.370-376, 2008.

BARBOSA, W.; CAMPO-DALL'ORTO, F.A.; OJIMA, M.; KALIL, G.P.C.; LOVATE, A.A.; RIBEIRO, I.J.A.; MARTINS, F.P.; NOGUEIRA, E.M.C. Incidência de ferrugem em folhas de pessegueiro e nectarineira do germoplasma IAC. Scientia Agricola, v.51, p.90-93, 1994.

CAMARGO, L.E.A.; BERGAMIM FILHO, A. Controle genético. In: BERGAMIM FILHO, A.; KIMATI, H.; AMORIM, L. (Ed.). Manual de fitopatologia: princípios e conceitos. 3.ed. São Paulo: Agronômica Ceres, 1995. v.1, p.729-760.

CENTELLAS-QUEZADA, A. Herança da época de floração e da resistência à ferrugem da folha em pessegueiro. 2000. 59p. Tese (Doutorado) - Universidade Federal de Pelotas, Pelotas.

CHAVES, M.S.; MARTINELLI, J.A.; FEDERIZZI, L.C. Resistência quantitativa à ferrugem-da-folha em genótipos de aveia-branca: I - Caracterização da reação em condições de campo. Fitopatologia Brasileira, v.29, p.39-46, 2004.

CITADIN, I.; BERTUOL, O.; BASSANI, M.H.; SOUZA, R.N. de; PINOTTI, L.C.A.; SOLETTI, T. Controle da ferrugem da folha de pessegueiro mediante pulverizações com diferentes fungicidas. Revista Brasileira de Fruticultura, v.27, p.317-319, 2005.

CRUZ, C.D. Programa GENES: análise multivariada e simulação. Viçosa: UFV, 2006. 175p.

JOHNSON, R.A.; WICHERN, D.W. Applied multivariate statistical analysis. $4^{\text {th }}$ ed. Upper Saddle River: Prentice Hall, 1998. 816p.

MARTINS, M.C.; AMORIM, L. Caracterização morfológica e especialização patogênica de Tranzschelia discolor em diferentes espécies de Prunus. Fitopatologia Brasileira, v.25, p.79-83, 2000.

MAY-DE MIO, L.L.; GARRIDO, L.; UENO, B. Doenças de fruteiras de caroço. In: MONTEIRO, L.B; MAY-DE MIO, L.L.; SERRAT, B.M.; MOTTA, A.C.; CUQUEL, F.L. (Ed.). Fruteiras de caroço: uma visão ecológica. Curitiba: UFPR, 2004. p.169-222.

OGAWA, J.M.; ZEHR, E.I.; BIRD, G.W.; RITCHIE, D.F.; URIU, K.; UYEMOTO, J.K. (Ed.). Compendium of stone fruit diseases. St. Paul: The American Phytopathological Society, 1995, 98p. (APS. Disease Compendium Series).

RASEIRA, M. do C.B.; CENTELHAS-QUEZADA, A. (Ed.). Pêssego: produção. Brasília: Embrapa Informação Tecnológica, 2003. 162p. (Frutas do Brasil, 49).

RASEIRA, M. do C.B.; NAKASU, B.H. Pessegueiro. In : BRUCKNER, C.H. (Ed.). Melhoramento de fruteiras de clima temperado. Viçosa, UFV, 2002. p.89-126. 
RODRIGUES, A.; SCARPARE FILHO, J.A.; ARAÚJO, J.P.C. de; GIRARDI, E.A.; SCARPARE, F.V. Intensidade de poda verde em pessegueiro para controle da ferrugem Tranzschelia discolor (Fuckel) Tranzschel e Litvinov. Revista Brasileira de Fruticultura, v.30, p.634-638, 2008.

ROUSE, R.E.; SHERMAN, W.B. Foliar rust resistance in low-chill peaches. Proceedings Florida State Horticulture Science, v.115, p.98-100, 2002.

SINGH, D. The relative importance of characters affecting genetic divergence. The Indian Journal of Genetics \& Plant Breeding, v.41, p.237-245, 1981.

SOTO-ESTRADA, A.; ADASKAVEG, J.E. Temporal and quantitative analyses of stem lesion development and foliar disease progression of peach rust in California. Phytopathology, v.94, p.52-60, 2004.
SOTO-ESTRADA, A.; FÖSTER, H.; DE MASON, D.A.; ADASKAVEG J.E. Initial infection and colonization of leaves of stems of cling peach by Tranzschelia discolor. Phythophatology, v.95, p.942-950, 2005.

SOUZA, S.R. de; MAY-DE MIO, L.L.; SERRAT, B.M.; CHALIOL, M.A. Doenças foliares, cancro e número de frutos relacionados com a adubação nitrogenada em pessegueiro. Revista Brasileira de Fruticultura, v.29, p.260-264, 2007.

VALE, F.X.R. do; PARLEVLIET, J.E.; ZAMBOLIM, L. Concepts in plant disease resistance. Fitopatologia Brasileira, v.26, p.577-589, 2001.

YORINORI, J.T.; KIIHL, R.A. de S. Melhoramento de plantas visando resistência a doenças. In: NASS, L.L.; VALOIS, A.C.C.; MELO, I.S.; VALADARES-INGLIS (Ed.). Recursos genéticos e melhoramento: plantas. Rondonópolis: Fundação MT, 2001. p.715-736.

$\overline{\text { Recebido em } 22 \text { de abril de } 2009 \text { e aprovado em } 10 \text { de novembro de } 2009}$ 